\title{
W. RADLOFF'UN TECRÜBESİ BİZE ÖRNEK OLMALI
}

\author{
Fenzile CEVHEROVA* - Gafur SÖNGATOV ${ }^{* *}$
}

Prof. Dr. Ferit Yusupov, “Сибирские татары. Из сокровищницы духовной культуры. Антология фольклора сибирских татар: дастаны, мунаджаты, баиты, Казань: изд-во Казанского ун-та, 2014. - 648 с. // Sibirya Tatarları. Manevi Kültür Hazinelerinden. Sibirya Tatarlarının Folklor Antolojisi: Destanlar, Münacat, Beyit, Kazan Üniversitesi Yay., Kazan 2014, -648 s.”

\section{Özet}

Türk Dil Kurumu haberleşme üyesi Filolog Prof. Dr. Ferit Yusupov’un “Сибирские татары. Из сокровищницы духовной культуры. Антология фольклора сибирских татар: дастаны, мунаджаты, баиты. Казань: изд-во Казанского ун-та, 2014. - 648 c". (Sibirya Tatarları. Manevi Kültür Hazinelerinden. Sibirya Tatarlarının Folklor Antolojisi: Destanlar, Münacat, Beyit. Kazan Üniversitesi Yay., Kazan 2014, -648 s.) adlı eserinde 19. yüzy1ldan başlayıp 20 yüzyıla kadarki dönemde derlenen destanlar, münacatlar ve beyitler toplanmıştır. Yazar, büyük araştırmacı-bilgin W. Radloff geleneğini devam ettirip sözlü halk edebiyatı ürünlerini tam bir transkripsiyon ile yazıya geçirmiştir.

Münacat ve beyitleri kendisi derleyip yazıya geçiren Ferit Yusupov bunların Tatar halkının diğer etnik gruplarındaki folklor eserleri ile ortak olduğunu, destanların da yalnızca Sibirya Tatarlarında korunup diğer Türk boylarındaki bu tür eserler ile benzerlik gösterdiğini söylemektedir. Derlenen malzemenin Rusçaya satır satır tercüme edilmesi, Sibirya Tatarları ve her türün özellikleri hakkında bilgi verilmesi kitabın okuyucu kitlesinin gayet büyük olacağını gösteriyor.

Anahtar Kelimeler: Sözlü Halk Eserleri, Manevi Kültür Ürünleri, Eser Metni, Destanlar, Münacatlar, Beyitler

\section{THE EXPERIENCE OF W. RADLOFF SHOULD SERVE AS A MODEL FOR US}

Prof. Dr. Ferit Yusupov, “Сибирские татары. Из сокровищницы духовной культуры. Антология фольклора сибирских татар: дастаны, мунаджаты, баиты, Казань: изд-во Казанского ун-та, 2014. - 648 с. // Siberian Tatars. From Spritual Cultural Heritages. Folflore Anthology of Siberian Tatars: Epics, Appeal, Couplet, Kazan University Yay., Kazan 2014, -648 p.”

\footnotetext{
Abstract

The book written by Philologist Prof Prof. Dr. Ferit Yusupov, a member of Turkish Language Society's communication branch, "Сибирские татары. Из сокровищницы духовной культуры. Антология фольклора сибирских татар: дастаны, мунаджаты, баиты.

${ }^{*}$ Doç. Dr., Cumhuriyet Geleneksel Kültürü Geliştirme Merkezi, Tataristan-Rusya. El-mek: zavgarova@inbox.ru

${ }^{* *}$ Cumhuriyet Geleneksel Kültürü Geliştirme Merkezi, Tataristan-Rusya. El-mek: gsungatov@ mail.ru 
Казань: изд-во Казанского ун-та, 2014. - 648 c". (Siberian Tatars. From Spritual Cultural Resources. Folflore Anthology of Siberian Tatars: Epics, Appeal, Couplet, Kazan University Yay., Kazan 2014, -648 p.) is a compilation of epics, appeals and couplets collected between 19th and 20th century. The author, following the tradition of great scholar and scientist W. Radloff, transfered the products of oral folk literature into writing with a full transcription.

Collecting appeals and the couplets himself Ferit Yusupov asserts that these are common with the works of other ethnic groups of Tatar people, while epics is preserved only in Siberian Tatars and have resemblence with the works of Turkish tribes. The collected material is translated into Russian verse by verse and it gives information about Siberian Tatars and each literary genre's characteristics. It appears that due to these factors, the book is likely to attract many people's attention.

Key Words: Oral Folk Literature Works, Spiritual Cultural Heritages, Text Of Work, Epics, Appeals, Couplets.

Millet ilerledikçe, halkların kültürel değerlerine ilgi de giderek artıyor. Avrupa ülkelerinde kültürle idare edilen kurumların en önemli yönelişi sözlü halk ürünlerini, kendi halklarının eski dönemlere ait günlük yaşam tarzlarını, örf ve âdetlerini, geleneklerini öğrenme olarak kabul ediliyor. Mümkün olanlarını yeniden hayata geçirme gibi projeler, bu alanlara ait en önemli meseleler arasına alınıyor. Zira, Avrupa halklarının kültürü tamamen yok olma tehlikesiyle karşı karşıya kalıp bu durum acımasız bir gerçeğe dönüştü. Bu açıdan bakıldığında bizim durumumuz da Avrupa halklarına yaklaşıyor, Tatarlarda bugün sözlü halk ürünlerinin pek çok türü tamamen yok oluyor. Bizim varlığımızı, bağımsızlığımızı korumak için kahramanlıklar gösteren bahadırlarımızı, tarihî şahsiyetlerimizi tasvir eden veya iki genç yüreğin sıcak, saf muhabbetiyle imrendiren destanlarımızı yüzlerce kişiye geceler boyu anlatan anlatıcılarımızı tarihin sert rüzgârları alıp götürüyor artık. Hayat tarzımızı kökünden değiştiren, kültürümüzü zayıflatan bu durumları birkaç nesil sezmedi bile. Daha bundan bir iki asır önce çok kişiyi imrendiren, hayran bırakan kültürel zenginliğimiz, eski eşyalar gibi çöpe atılır, dağılır, kaybolur diye aksakallarımız akıllarına dahi getirmemişlerdir.

Bu korkunç kaderi kendi başlarından geçiren Avrupalı âlimler, Rusya İmparatorluğunda kültürel bakımdan en zengin olan Türk boylarının da bu hâle düşeceklerini önceden bilerek hareket etmişler, kültürel değerleri güçlerinin yettiği kadarıyla gelecek nesillere ulaştırma çabasına girmişlerdir. Bu kıymetli zatlardan biri, Wilhelm Fredrihoviç (Vasiliy Vasilyeviç) Radloff'tur. 1837 yılında Almanya'nın Berlin şehrinde doğan W. Radloff, çocukluğundan itibaren çok çalışkan ve yeteneklidir. 1854 yılında lise eğitimini başarıyla tamamlayıp Berlin Üniversitesi Felsefe Fakültesine girer. O dönemlerde bu tür fakültelerde dil, tarih, antropoloji bilimleri de okutulmaktadır. Çeşitli dillerin kökenlerine hasredilen eserleriyle tanınan, dillerin tarihî karşılaştırma metoduyla öğrenilmesine temel atan ünlü Avgust Pott'un derslerini susamışçasına dinlemek Radloff'un ömür boyu sürecek meşguliyetine itici bir güç olur. Yine de onun gerçek bir doğu dilleri bilgini olmasında, Ural-Altay dilleri teorisinin gelişimine önemli katkılar sağlayan W. Scott ile olan yakın münasebeti vesile olur. Hocalarının dilbilimin sihirli sayfaları hakkında söyledikleri, delikanlıyı bütün hayatını Rusya'nın Asya kısmında yaşayan Türk halkları, öncelikle Sibirya Tatarlarının dili, tarihi ile ilgili çalışmalara yönelmesi kararını aldırır. 1858 yılında Radloff, o dönem dünyanın en ünlü üniversitesi olan Berlin Üniversitesini bitirdikten sonra ünlü hocası W. Scott'un Rusyanın tanınmış Türk dilleri bilgini O. Böhtlink'e öğrencisi Radloff'a yardım etmesini rica eden mektubunu alıp binbir güçlükle St. Petersburg'a ulaşır. Onun en büyük hayali Batı Sibirya'da yaşayan, o döneme kadar bilimsel bakımdan hiç kimse tarafından araştırılmayan Tatarların bulunduğu yerlere gitmek, onların tarihi, dili, örf ve âdetleri hakkında bilimsel araştırma işini başlatmak olur. Fakat, o dönemlerde Rus hükûmeti o bölgelere yabancıların gitmesine izin vermemektedir. Radloff, dünyadaki en büyük hayalini hayata geçirmek için Almanya vatandaşlı̆̆ını terk edip, Rus vatandaşlığı almaya mecbur kalır. 
O andan itibaren Fredrih Wilhelm Rus vatandaşlığına geçip Vasiliy Vasilyeviç adını alır. Genç adamın bu cesaretini Rus kamuoyu şaşkınlık ve hayranlıkla kabul eder. Bu durum üzerine aradan üç gün de geçmeden genç âlime Sibirya yolu açılır ve Avrupa'nın sıcak tabiatına göre hafif şeyler giyinen Vasiliy, atlı kızağa binerek Barnaul'un yolunu tutar.

W. Radloff kışları Barnaul Meslek Yüksekokulunda Alman, Latin dillerini öğretmekle meşgul olsa da yazın Tatar ve diğer Türk boylarının yaşadığı bölgelere bilimsel araştırma gezileri düzenler. $\mathrm{Bu}$ gezilerde derlenen malzemeler temelinde W. Radloff'un "Obrazts1 narodnoy literaturı tyurkskix plemen, jivuşçix v Yujnoy Sibiri i Djungarskoy stepi. Çast IV. Nareçie Barabintsev, Tarskix, Tobolskix i Tyumenskix tatar/Güney Sibirya ve Çungarya Bozkırlarında Yaşayan Türk Boylarının Halk Edebiyatı Örnekleri. Bölüm IV. Baraba, Tara, Tobol ve Tümen Tatarları Lehçesi, St. Petersburg, 1872" adlı kitabı yayımlanır. Bu eserle Rus Türkoloji mektebi, özel olarak da Tatar halkbilimi başlamıştır diye kabul edilir. Kitaba Sibirya Tatarlarının masalları, 680 dizeden oluşan 29 türkü, halk hikâyesi ve destanlar olmak üzere toplam 121 derleme metni alınmıştır. Radloff'un doğumunun 175. y1lı hatırasına bu hacimli eseri 2012 y1lında Kazan Federal Üniversitesi öğretim üyesi Prof. Dr. Ferit Yusupov Kazan'da yayımladi.

Maalesef, W. Radloff'un bu eserinden sonra Sibirya Tatarlarının halk edebiyatı eserleri onun prensiplerine göre ele alınmamış, yani konuşulduğu gibi derlenip transkribe edilerek yayımlanmamıştır. W. Radloff'a gönderme yapılan bir makaleden diğerine aktarılan bir iki cümlelik övgü dışında, onun büyük eserine gereken değer verilmedi, ne kadar büyük bir iş başardığını ortaya koyan bir tek makale dahi yazılmadı. Nihayet, son yıllarda bu alanda ilerleme görüldü. Kazan Federal Üniversitesi öğretim üyesi Prof. Dr. Ferit Yusupov, Radloff'un hayatı ve bilimsel eserleri üzerine ondan fazla bilimsel makale yayımladı, yabancı ülkelerde ve Rusya'da düzenlenen uluslararası sempozyumlarda bildiriler sundu.

Son yıllarda milletlerin daha çok ilişkiler kurması, farklı ülkelere, bölgelere has özelliklerin kaybolması devrinde, onların manevi değerlerini canlandırmak, öğrenmek, eski geleneklerin, örf ve âdetlerin, inançların, ülkülerin açıklanması ve onlara karşılaştırmalı olarak kıymet verilmesi ihtiyacı daha fazla arttı. Tatar ve diğer Türk ülkelerinin bilim adamları, araştırmacıları bu alanda büyük işler başarıyor. Filoloji profesörü, Türk Dil Kurumunun haberleşme üyesi Ferit Yusupov tarafından hazırlanıp yayımlanan "Sibirskie tatarı. İz sokrovişçnitsı duxovnoy kulturı. Antologiya folklora sibirskix tatar: dastanı, munadjatı, baitı. Kazan: izd-vo Kazanskoğo un-ta, 2014. -648 s.” (Sibirya Tatarları. Manevi Kültür Hazinelerinden. Sibirya Tatarlarının Folklor Antolojisi: Destanlar, Münacat, Beyit. Kazan Üniversitesi Yay., Kazan 2014, -648 s.) adlı eser, bu zaruri ve önemli hizmetlerden biridir.

Ferit Yusupov'un Sibirya Tatarlarının dilini, örf ve âdetlerini araştırmak için ömrünün elli yıldan fazlasını sarf ettiği hepimizin malumudur. Saklanan yadigârları arayıp bulmayla ilgili olarak tecrübeli bilim adamının kendi fikri var. Belirli bir yere derlemeye gittiğinde o malzeme toplamak için bütün ayrıntıları gözde tutarak tüm imkânlarını seferber ediyor. Mesela, dil özelliklerini araştırırken bölge tarihine ait masal ve halk hikâyeler de, her çeşit folklor eserleri de, etnografik malumatlar da yazıp alınıyor. Sözünü ettiğimiz kitap da bilim adamının ömür boyunca bir amaç uğruna ve ayrıntılı çalışmasının, manevi yadigârlarımızın derlenmesi yolunda bir fedai gibi hizmet edişinin meyvesidir. "Halkta artık derlenecek malzeme kalmamış, olanları çoktan derlemişler, şimdikiler bir şey bilmiyor" diyenlere Ferit Yusupov kendisinin topladığ 1 ve adı geçen esere alınan malzemenin derlenme tarihine bakmak lazım. Münacat ve beyitlerin bir kısmı 1980'lerde, diğer bir bölümü 2010'lu y1llarda derlenmiş. Demek, birçok bölgede hâlâ kuşaklar arası zincir kopmamış, o, çeşitli fedakârların samimi gayretleri, atalarının mirasına olan muhabbetiyle günümüze kadar sürekli yenileniyor.

Eser, adından göründüğü kadarıyla, Sibirya Tatarlarının sözlü halk ürünlerinden lirik destani türlere hasredilmiştir. Bunlar; destanlar, münacatlar ve beyitlerdir. İçeriğine ve yapısına bakıldığında kitabın düzeninin dünya ve Türk dil bilimi kazanımlarının gözde tutularak ve uzun 
y1llık tecrübeye dayanılarak yeni bir bilimsel temele oturtulduğu fikri doğmaktadır. Öncelikle şunu belirtmek gerekir ki, bu eser Sibirya Tatarlarının halk edebiyatı eserlerinin bir araya getirildiği ilk antolojidir. $\mathrm{Bu}$, şimdiye kadar bu alanda bulunan boşluğu dolduran bir adım olması bakımından da önemlidir. Çünkü, Tatar halkını meydana getiren başlıca üç etnik grubun, Kazan Tatarlarının, Mişerlerin ve Sibirya Tatarlarının halk edebiyatı ürünlerini bir araya toplandığ başka bir antoloji yoktu. Folklor metinlerinin Radloff'un eserinde olduğu gibi Sibirya Tatarlarının konuşma diliyle transkribe edilerek verilmesi kitabın bir başka önemli tarafıdır. Bu, Sibirya Tatarlarının manevi kültürünü korumada önemli çarelerden biridir. Bu usul şüphesiz ileride yayımlanacak eserlere de dayanak olmalıdır. Türk folkloru üzerine çalışan pek çok bilim adamı, folklor metinlerini Tatar edebî diline aktarıp durmayı ilgiyle yapıyorlardı. Yazar; W. Radloff, N. F. Katanov, D. G. Tumaşeva, L. V. Dmitriyeva vd. ünlü Türkologların kullandığı ve şimdiki bilim adamlarının iyi bildiği Rus akademik transkripsiyonundan faydalanıyor. Bilim adamları arasında geniş̧e yayılan transkripsiyonu kullanmak, metinleri okumayı oldukça kolaylaștırıyor. Bu bilimsel yöntem, halk edebiyatı eserlerini derlendiği gibi okumaya, her kelimenin ahengini belirli bir ağızdaki ahengini hissetmeye imkân veriyor. Metinler, birebir satır satır tercüme edilmelerine rağmen Rusçada da gayet güzel yankılanıyorlar. Bu, şüphesiz, yazarın Sibirya Tatar ağızlarını iyi bilmesinden kaynaklanıyor.

Kitabın önemli bir kısmında Sibirya Tatarlarının ortaya çıkışı, şekillenme tarihinin aydınlatılması ele alınmaktadır. Yazar, Sibirya Tatarlarını Tatar halkının oluşumuna katkıda bulunan üç temel etnik gruptan biri olarak görüyor ve onların Batı Sibirya düzlüklerinde miladın başlarına kadar yaşayan diğer Türk boylarıyla birleştiklerini, milattan sonraki bin yılda daimi surette bölgeye gelen Sünler, Kıpçaklar vd. Türk boyları ile karıştıklarının altını çiziyor. Bunun dışında, asırlar devamında Sibirya Tatarları, İdil-Ural boylarından göç eden Bulgarlar, komşu Başkurt, Kazak, Nogay kabileleri ile de sıkı bir ilişkide olmuşlardır. Onların şekillenmesinde çeşitli zamanlarda, özellikle de Kazan Hanlığı dağıldıktan sonra, doğuya doğru göç eden Kazan Tatarlarının da rolü büyük olmuştur. Ferit Yusupov, İdil-Ural taraflarından gelen Kazan Tatarlarının yeni köyler kurduklarından veya Sibirya Tatarlarının köylerinde yaşamaya devam ettiklerinden bahsediyor. Elbette, onların çabucak kaynaşıp bir olmalarında yalnızca aynı dili konuşmaları değil dinî ortaklıkları da etkili olmuştur. İslam dini ise, Ferit Yusupov'un kitabında anlatıldığına göre, Bulgarlar vasıtasıyla gelmeye başlamıştır. Bunun dışında, Sibirya Hanlarının isteği üzerine Orta Asya'dan özel olarak getirilen İslam misyonerlerinin de gayreti çok olmuştur. Bilim adamı bu bilgileri çok sayıda tarihî-etnografik, kültürel kaynaklara dayanarak veriyor. Eskiden beri birbirine yakın akraba boy ve kabilelerden oluşan Tatarlar, Tobol-İrtiş bölgesinde müstakil olarak kendi devletçiklerini kurmayı başarmışlar, Rus devleti tarafından işgal edildikten sonra asırlar boyunca millî ve dinî baskılara maruz kalmışlardır. İdil boyu Tatarlarından uzak yaşamak, Tatar edebî dilinin azalması da bu kardeşlerimizin millî-kültürel gelişimini engelleyen faktörlerdendir. Yoksa, yazarın belirttiği üzere, İdil boyu Tatarlarında olduğu gibi Sibirya Tatarlarında da hayvancılık ve çiftçilik işleri ileri gitmiş, hatta onlar madencilikle de uğraşmışlardır.

Kitaptaki "Sibirya Tatarları" başlıklı giriş kısmı, geniş bir okuyucu kitlesinin anlayacağı dille, bilimsel-popüler tarzda yazılmış olup dar bir çevreye hitap eden pasif terimlerden arındırılmıştır. Bu durum, geniş hacimli kitabın yalnızca bilim adamlarına değil kültür, eğitim, iletişim alanlarında çalışanlara, genellikle, halkın manevi mirası ile ilgilenenlerin tamamına yönelik olarak hazırlandığını göstermektedir. Bu eserde Sibirya Tatar ağızlarının asıl fonetik ve gramatik özellikleri hakkında da bilgi var. Ferit Yusupov, diğer Tatar ağızlarıyla birlikte Sibirya Tatar ağızlarının asıl fonetik özelliklerini aydınlatıp morfolojik sistemini belirginleştirerek diyalekt dili düzleminde inceleyen bir bilim adamıdır. Yazar, Sibirya Tatarlarının yaşadığı tüm bölgelerde dağılan ağızların Tatar Türkçesinin Orta ve Batı ağızlarından ayrılan karakteristik özelliklerini gösteriyor. Eserde Sibirya Tatar ağızlarının Orta ağız grubu ile benzer olup Mişer ağızlarından farklı olan ve Mişer ağızları ile aynı olan özelliklerinin Orta ağız grubundan farklı olan ortak yönleri olduğu da belirtiliyor. Mesela, Sibirya Tatar ağızlarının fonetik sistemi y'leştirici, ts'leştirici olması ve /ç/ sesinin patlamalı olarak söylenmesi, /a/ ünlüsünün daha açık 
söylenmesi bakımından Mişer ağızları ile benzerdir ve durum onları Orta ağız grubundan ayırmaktadır. Kalın k, g seslerinin olması, dudak uyumunun güçlü olması gibi ayırıcı özellikleri ile de Orta ve Doğu grubu ağızları, Batı ağız grubundan ayrılmaktadır vb.

Yeri gelmişken bütün ömrünü Tatar halkının dilini, manevi yadigârlarını araştırmaya, bu bilgileri genç nesle aktarmaya adayan Ferit Yusupov'un yazı ve konuşma tarzına ayrıca değinmek uygun olur. Bilimsel konferansta mı konuşuyor, ders mi anlatıyor, herhangi bir konu hakkında fikir mi beyan ediyor veya bilimsel bir eser mi yazıyor, hepsi de dinleyiciye ve okuyucuya anlaşı1ır bir tarzda veriliyor. Karmaşık bilimsel tartışmalarda da kendi fikrini mükemmel bir şekilde ve delillendirerek "ben bilirim"in dışında anlatması şüphesiz pek çok kişinin erişemeyeceği bir yüceliktir. "Sibirya Tatarları. Manevi Kültür Hazinelerinden" adlı kitapta destanlar, münacatlar ve beyitlerin manevi-kültürel kıymeti, fikrî-estetik özellikleri hakkındaki makaleler de, zaten geniş hacimli antolojinin çok sayfasını işgal etmeden, titizlikle ortaya konuyor ve okuyucuya zengin bir bilgi veriyor.

Kitapta yer alan lirik-destani eserlerin büyük çoğunluğunu destanlar teşkil ediyor. Zamanında bunları ilk olarak W. Radloff derlemiş ve meşhur "Halk Edebiyatı Örnekleri..." adlı eserine Tümen, Tara, Tobol, Baraba Tatarlarından alınan 16 destan koymuştur. Radloff, o sıralarda Sibirya Tatarlarında bulunan destanların pek çok Türk boyunda korunan bu gibi lirikdestani eserlerle benzer olduğunu söylemiştir. 20. yüzyılın ikinci yarısında Tatar folklorcuları X. Yarmi, F. Exmetova, F. Urmançeyev, X. Gatina, L. Camaletdinov, N. İbrahimov, X. Mexmutovlar büyük bilim adamının izinden derleme gezileri düzenlemişler ve 19. yüzyılda destanların derlendiği köylerde bunların çoğunun artık korunmadığını görmüşlerdir. Ferit Yusupov'a da kaybolmakta olan destanların farklı parçalarını derlemek nasip olur, yine de bu parçalar bilim için büyük öneme haiz olan malzemelerdir.

Destanlardan bahsedilirken yazar, onların Sibirya Tatarlarında daha çok yayıldığını ve korunduğunu belirtir. Kazan ve diğer İdil boyu bölgelerinde ise sözlü destanlar daha önce yok olmuşlardır. Kazan Tatarları, Türk halkları arasında daha fazla ilim sahibi olup yazılı kültürü geliştirmeye ağırlık vermişlerdir. Sibirya Tatarları folkloru son devre kadar destan türünün az da olsa koruna gelmesi bakımından özelliklidir. Ferit Yusupov'un fikirlerinden anlaşıldığ kadarıyla, bu durum Sibirya Tatarlarının büyük yol güzergâhlarından uzakta, sazlık yerlerde, göller-nehirler arasında yaşayıp geleneksel yaşam tarzlarını sürdürmeleri, başkalarının etkilerine az maruz kalmalarından kaynaklanmıştır. Yazar, destanları bir amaca yönelik olarak araştıran bilim adamlarının fikirlerine dayanarak (W. Radloff, F. V. Exmetova, M. İ. Exmetcanov, M. X. Bakirov vd.) Sibirya Tatarlarından derlenen epik eserlere tür olarak yaklaşıyor, malzemenin önemli taraflarına dikkatini yöneltiyor. Mesela, destanlarda İslami geleneklerle birlikte yerli örfâdetler, gelenekler de yansımasını buluyor.

Çeşitli türlere ait eserler hakkında bilgi verme kitabın sonunda bulunan "Notlar" kısmında da devam ediyor. Burada antolojiye alınan halk cevherlerinin ne zaman kim tarafından derlendiği, Rusçaya tercüme eden yazarlar ve basılanların kaynakları gösterilmiş̧ir. Burada "Karatsa" destanın hakkında söylenen bir fikrin üzerinde ayrıca durmamak olmaz. W. Radloff, Sala adlı köyde derlediği bu destanın kahramanı Karaça tarihî bir şahıstır. O, Küçüm Hanın yanında Ruslara karşı birçok savaşa katılmıştır. "Karatsa"yı Rusçaya tercüme eden ve F. V. Exmetova ile düzenleyen kitap yazarı olan A. V. Prelovskiy Rus elyazmalarında bu büyük şahıstan sıkça bahsedildiğini yazıyor. En önemlisi, destanın anlatı kökleri 8. yüzyıla ait olup uzun asırlardan sonra W. Radloff tarafindan incelenen ve okunan Eski Türk Yenisey mezar taş1 yazılarına kadar gittiğini gösteriyor. Bilgin, Karaça'nın iki genç savaşçı oğlu öldürüldükten sonra kederini anlatışını, "Kahramanlara Adanan Yazmalar”da Bilge Kağan'ın kardeşi Kültigin öldürülünce ağlamasının tasvir edilmesine çok benzediğini söylüyor. Bu iki eserin arasında bin bin yıla yakın zaman olsa da onların kuruluşları ve kayg1-hasret gücünü, derinliğini yansıtmaları bakımından çok yakın olmalarına hayret ettiğini belirtiyor. "Eski şiirleri kelimesi kelimesine korumak için halk hafizasının ne kadar güçlü ve sağlam olması gerek! Gerçekten de şiir ölümsüz!” diye yazıyor, Anatoliy Prelovskiy. Bu ilginç bilgileri Ferit Yusupov'un kitaba alması 
bilim ve bilim adamlığ bakımından çeşitli seviyelerde bulunan okuyuculara halk edebiyatı ürünlerini doğru şekilde anlamaya yardım ediyor.

Destanlardan farklı olarak münacatların ve beyitlerin yayılımı pek geniş, bunlar Tatar halkının yaşadığı her bölgeye hastır. Bu türlere giren eserlerin halen daha üretilmesi ve aktif olarak kullanılmaları bunların gerçek anlamda millîliklerini, halka ait olduklarını, Tatar insanının can avazını yansıttıklarını gösteriyor. Sibirya Tatarlarından derlenen münacatlar ve beyitlerden bahsedilirken onlara değer biçmede ve sınıflamada Ferit Yusupov folklor alanında büyük çabası ile tanınan ünlü Tatar bilgini M. X. Bakirov, münacatları derleyip gün yüzüne çıaran A. X. Sadekova, beyitleri toplama ve araştırma işiyle uğraşan F. V. Exmetova'nın çalışmalarına da dayanıyor. Şurası da dikkate değerdir ki, kitaba konulan her münacat ve bir ikisi dışında beyitlerin hepsi de Ferit Yusupov'un rehberlik ettiği derleme gezilerinde kaydedilmiş, kendisi tarafından transkribe edilmiş ve onun gözetiminde Rusçaya tercüme edilmiştir. Yusupov'un yaptığı değerlendirmelerden Sibirya Tatarlarına ait münacatların ve beyitlerin halkımızın başka bölgelere yayılan eserleri ile ortaklıklar gösterdiği anlaşılıyor. Sibirya Tatarlarında yayılan, Kazan Hanlığının yıkılışının felaket olarak tasvir edildiği "Han Mescidi Beyti" gibi örnekler Tatar halkının çeşitli etnik gruplarının ortak bir tarihî kadere sahip olduklarını gösteriyor, manevi kültürümüzün aynı olduğunu daha da sağlam olarak anlamamıza yardım ediyor. Sonuç olarak bundan yüzlerce yıl önce de, şimdi de halkın bilincini, gönlünü aksettiren, insanların yaşam tarzlarını, ruh hallerini tasvir eden ve insanların kendi ağzından çıkan cevherlerin kitap olarak gün yüzüne çıkması halkımızın kültür tarihini çeşitli yönelişlerde karşılaştırıp incelemeye zengin, güvenilir malzemeler veriyor. 